\title{
Study on Ice Parameters Affecting DP Performance of FPSO in Arctic Ocean
}

\author{
Sol-Mi Choi ${ }^{*}$, Seung-Jae Lee*, Solyoung $\operatorname{Han}^{* *}$ and Jaeyong Lee ${ }^{* * *}$ \\ "Division of Naval Architecture and Ocean Systems Engineering, Korea Maritime and Ocean University, Busan, Korea \\ ${ }^{* *}$ Offshore Floater Research, Samsung Heavy Industries Co., LTD, Daejeon, Korea \\ *** Department of Naval Architecture and Ocean Engineering, Dong-eui University, Busan, Korea \\ 극지용 FPSO의 DP 성능에 영향을 미치는 빙 파라미터 분석에 관한 연구

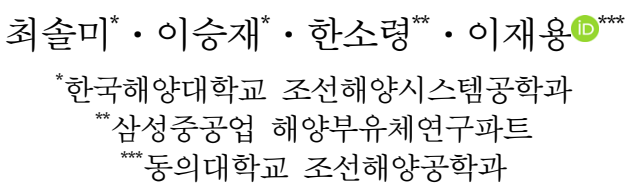

KEY WORDS: Dynamic positioning system 동적 위치유지 시스템, DP capability plot DP 성능 도표, Ice load 빙하중, GPU-eventmechanics GEM, Arctic FPSO 극지용 부유식 생산 저장 하역 설비

ABSTRACT: Recently, various efforts have been made to develop oil and gas in the Arctic Ocean. It is very important to consider the load caused by ice in designing floating structures in the area. The magnitude of the ice load and its impact on a structure should be considered. In this paper, we analyze ice parameters affecting the DP performance of FPSO with a DP-assisted mooring system. Several ice characteristics are selected, and the resulting ice load is calculated using GEM software. Numerous simulations are conducted while changing the values of the parameters, and DP capability plots are generated to visualize the effects of changing these parameters. It is shown that the ice drift speed and thickness are the major properties to be considered in DP system design. The limitations of the analysis and future work are discussed in the conclusion.

\section{1. 서 론}

최근 낮은 원유 및 가스 가격에도 불구하고, 증가하는 원유의 수요에 따라 장기적인 관점에서 수심이 깊은 해역 및 극지방의 에너지 개발이 활발히 진행될 것으로 예상되고 있다. 동적 위치 유지 시스템(Dynamic positioning system, DPS)은 이러한 환경에 서 운용되는 생산 플랫폼의 위치유지를 능동적으로 수행할 수 있어 단독으로 혹은 계류 시스템과 함께 사용되고 있다. FPSO (Floating production storage and offloading)의 동적 위치유지 시 스템은 설계단계에서 대상 해역을 기준으로 한 성능평가가 매 우 중요하다. 동적 위치유지 시스템의 성능은 목적에 따라 다양 한 방법으로 검토가 이루어지며 대표적인 검토 방법에는 DP (Dynamic positioning) 성능 분석(DP capability analysis), 시간 영 역 해석, 드리프트-오프와 드라이브-오프 시뮬레이션(Drift-off and Drive-off simulation) 등이 주로 사용되고 있다. DP 성능 분
석은 주어진 환경조건에서 대상 선박에 설치된 추진기의 위치 와 용량이 위치유지를 할 수 있는지에 대한 정적 해석을 수행 하는 것이다. 일반적으로 IMCA(International Marine Contractors Association)의 규정서(Specficiation)에 명시된 DP 성능 분석을 위한 환경 외력 계산과정 및 추력 손상 등의 분석 시나리오가 사용된다(IMCA, 2000). DP 성능 분석의 결과는 통상적으로 Wind envelope와 Thrust envelope 로 대표되는 DP 성능 도표(DP capability plot) 형태로 나타낸다. 이 DP 성능 도표들은 풍력, 파 력 및 조류력을 포함하는 일반적인 환경 하중에 대한 DP 성능 을 나타낸다. 극지방의 경우 DP 성능 평가를 위하여 환경 외력 에 빙하중을 반드시 고려해야 한다. 하지만, 빙하중의 경우 다 양한 빙 파라미터들로 인한 하중의 변동성이 존재하기 때문에 환경 외력에 포함하기 위한 정량화된 값을 산출하기 어려운 점 이 있다. Kerkeni et al.(2013)은 쇄빙 된 빙(Managed ice)조건에 서의 CFD(Computational fluid dynamics)기반 수치해석 시뮬레이

Received 22 December 2017, revised 5 February 2018, accepted 5 February 2018

Corresponding author Jaeyong Lee: +82-51-890-2596, jlee@deu.ac.kr ORCID: http://orcid.org/0000-0002-4469-7765

(c) 2018, The Korean Society of Ocean Engineers

This is an open access article distributed under the terms of the creative commons attribution non-commercial license (http://creativecommons.org/licenses/by-nc/3.0) which permits unrestricted non-commercial use, distribution, and reproduction in any medium, provided the original work is properly cited. 
션을 수행하여 환경 외력의 비선형적인 요소들을 포함한 시간 영역 기반의 DP 성능 도표를 산출하였다. 산출 결과로부터 빙 밀집도와 표류 속도에 따른 위치유지 성능을 평가하였다. Su et al.(2013)은 다양한 빙 파라미터를 고려한 실험을 통해 빙하중의 시계열 변화를 통계적으로 처리하여 DP 성능 도표를 산출하였 으며 빙 파라미터들 중 두께와 표류 속도의 변화에 대한 DP 성 능 도표를 나타내었다. 빙 조건에서의 DP 성능 도표에 관한 기 존 연구들은 산출법 제시에 우선순위를 두고 있으며 다양한 빙 파라미터들의 변화에 따른 DP 성능의 변동성은 명확하게 분석 되지 않았다. 빙 파라미터의 종류는 매우 다양하며 해양 구조물 의 목적에 따라서 우선시 되어야 할 파라미터의 종류도 달라진 다. 따라서, 목적에 따라 빙 파라미터들의 영향도를 분석하여 어떤 파라미터들을 중점적으로 시뮬레이션에 포함해야 할지 판 단할 필요가 있다. 본 연구에서는 $\mathrm{ARC7}$ 이라는 구체적인 빙 등 급(Ice class)을 대상으로 한 북극해에서, DP 성능에 영향을 주는 빙 파라미터들을 분석하였다. 분석에는 IMCA의 $\mathrm{DP}$ 성능 도표 산출법을 기반으로 빙 조건을 추가하여 산출된 두 가지의 성능 도표를 사용하였으며, 민감도 분석을 통해 파라미터별 해석상 중요도를 판단하였다.

\section{2. $\mathrm{DP}$ 성능 도표}

$\mathrm{DP}$ 시스템(DPS)의 정적 성능평가는 일반적으로 극좌표계 형 태의 DP 성능 도표를 통해 분석할 수 있다. DP 성능 도표의 분 석은 다양한 환경조건에서의 직접적인 DPS 성능 비교가 가능 하며 시간영역 해석보다 시뮬레이션 과정이 간단하여 적은 계 산시간이 소모되기 때문에 보통 설계 초기 단계에서 유용하게 활용되며 운용 중인 선박의 Dynamic positioning operator(DPO)들 을 위한 자료로도 사용된다. 반면에, 환경 외력의 동적인 요소 와 선박과 추진기 및 추진기간의 간섭효과 등을 정확하게 고려 할 수 없다는 단점이 존재한다.

\subsection{DP 성능 도표의 종류}

앞서 기술한 바와 같이 DP 성능 도표에는 2 가지 종류가 가장 널리 사용된다. Wind envelope는 주어진 조건에서 선박의 위치 유지가 가능한 최대 풍속을 나타낸다. Thrust envelope는 제시된 환경조건에서 위치유지를 가능하게 하는 모든 추진기의 각 가 용출력 대비 필요출력의 비가 가장 높은 추진기의 비를 표시하 여 나타낸 도표이다. 가용출력은 추진기가 발생시킬 수 있는 최 대 추력을 의미하며 추진기마다 고유의 값을 가진다. 필요출력 은 해당 환경조건에서 위치유지를 위해 추진기에게 요구되는 추력이다. 필요 출력은 환경 하중의 상태에 따라 변화하며 각 추진기마다 다른 값을 가질 수 있다.

\section{$2.2 \mathrm{DP}$ 성능 도표의 산출법}

일반적으로 $\mathrm{DP}$ 성능 분석은 IMCA의 기준 규정서(Standard specification)에 명시된 사항을 수행하게 된다. 분석에 적용되는 환경 외력은 보통 풍력, 파력 그리고 조류력이다. 풍력과 조류 력의 경우 환경 요소들의 방향에 따른 대상 선박의 투영면적과 환경계수에 따라서 계산될 수 있으며, 파력은 IMCA의 풍속-파
도의 관계표에 나타난 파 관련 지표들을 사용하여 계산된다. $\mathrm{DP}$ 성능 도표의 종류에 따라서 산출하는 방법에 차이가 있으 며, 일반적으로 세 가지 환경 하중이 모두 동일한 방향에서 작 용하는 것으로 가정한다.

\subsubsection{Wind envelope}

Wind envelope을 그리는 순서는 Fig. 1과 같다. IMCA에 따라 정의된 모든 환경 외력들의 합력에 대응하기 위해 추력 분배 알고리즘이 추진기별 필요추력을 산출한다. 식 (1)에 따라 산출 된 필요 추력이 추진기별 가용 추력 이상의 값을 가질 때까지 Table 4에 명시되어 있는 IMCA의 평균 풍속 간격에 따라서 풍 속을 상승시키며 반복적으로 시뮬레이션한다. $\vec{F}_{t h}$ 는 추진기들이 생성시켜야 하는 필요추력이며 $\vec{F}_{w i}$ 는 풍력, $\vec{F}_{w a}$ 는 파력, $\vec{F}_{c u}$ 는 조류력이다. 추진기별로 할당된 필요추력이 가용추력 이상의 값을 가질 때, 환경외력 요소 중 풍속이 성능 도표에 표시된다. 이 때의 환경조건이 DPS가 위치유지를 가능하게 하는 최대 환 경 외력임을 알 수 있다. 완전한 Wind envelope는 주어진 환경 외력의 방향 개수만큼 시뮬레이션하여 도출할 수 있다.

$$
0=\vec{F}_{t h}+\vec{F}_{w i}+\vec{F}_{w a}+\vec{F}_{c u}
$$

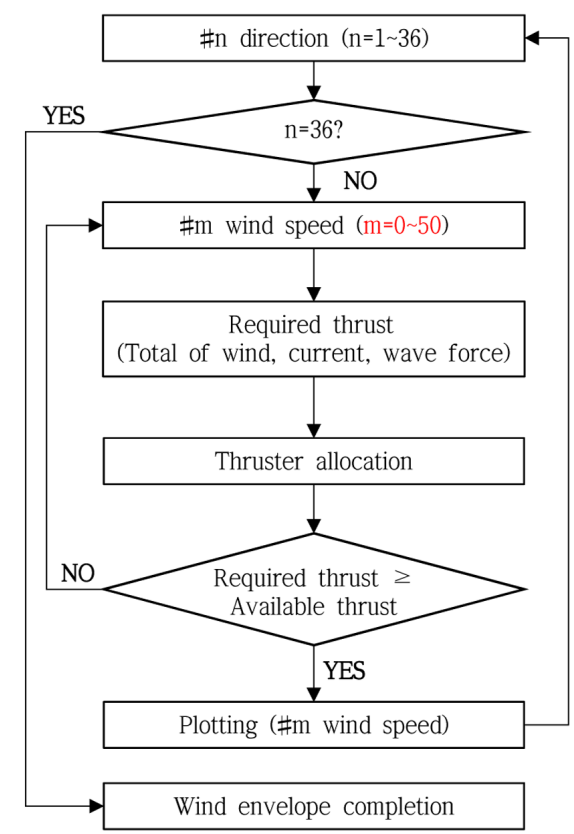

Fig. 1 Generation procedure for wind envelope

\subsubsection{Thrust envelope}

Thrust envelope은 보통 Fig. 2에 나타난 순서에 따라 작성된 다. 주어진 환경조건과 환경요소들의 방향이 설정되면 환경외 력이 계산된다. 계산된 환경 외력은 Wind envelope와 같이 추력 분배 알고리즘을 통해 추진기별로 필요추력이 분배된다. 이때, 모든 추진기의 가용추력에 대한 필요추력의 비중 가장 큰 추진 기의 비율이 성능 도표에 작성된다. 본 과정이 환경외력의 방향 개수에 따라 반복되면 최종적으로 Thrust envelope가 결정될 수 있다. 


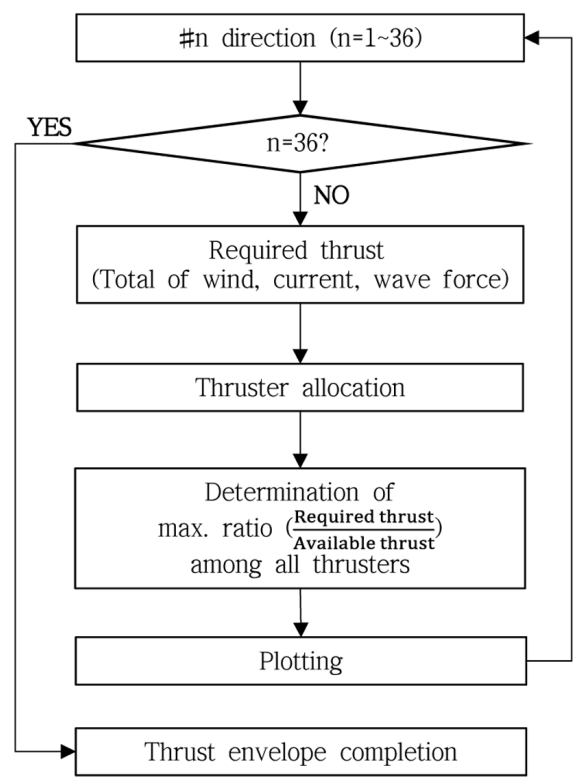

Fig. 2 Generation procedure for thrust envelope

\section{3. 시뮬레이션 파라미터}

\section{1 대상선과 추진기 모델}

$\mathrm{DP}$ 성능 도표 도출을 위한 시뮬레이션에 사용된 대상 선박은 원유 생산 설비인 FPSO선으로 최대적재 조건을 고려하였다. 주 요 제원은 Table 1에 명시하였으며 대상 선박의 모델은 Fig. 3에 나타내었다. DPS를 위한 제어장치는 2개의 터널 추진기(Tunnel thruster)를 선수부에, 3개의 전방향 추진기(Azimuth thruster)를 선미부에 배치하였다. 각 추진기의 최대추력과 배치도는 Table

Table 1 Principle dimension of target vessel

\begin{tabular}{cc}
\hline \hline Principal dimension & Value \\
\hline Length between perpendiculars(LBP) [m] & 244 \\
Breadth [m] & 50 \\
Draft [m] & 18.6 \\
Displacement [m $\left.{ }^{3}\right]$ & 163215 \\
GM [m] & 4.43 \\
Vertical center of gravity(VCG) [m] & 18.5 \\
Radius of gyration for $x[\mathrm{~m}]$ & 15.2 \\
Radius of gyration for $y[\mathrm{~m}]$ & 59.3 \\
\hline Radius of gyration for $z[\mathrm{~m}]$ & 60.0 \\
\hline
\end{tabular}

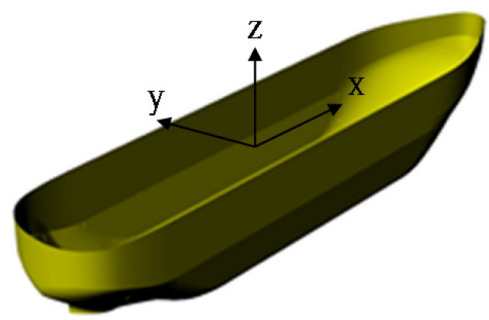

Fig. 3 Geometry of target model
Table 2 Principle dimension of actuators and arrangement

\begin{tabular}{|c|c|c|c|}
\hline No. & Type of thruster & $\begin{array}{c}\text { Thrust } \\
{[\mathrm{kN}]}\end{array}$ & Thruster arrangement \\
\hline 1 & Tunnel thruster & 330 & $113 \mathrm{~m} * 86 \mathrm{~m}$ \\
\hline 2 & Tunnel thruster & 330 & \\
\hline 3 & Azimuth thruster & 875 & (4) $\frac{v}{2}$ \\
\hline 4 & Azimuth thruster & 875 & (5) \\
\hline 5 & Azimuth thruster & 875 & $122 m$ \\
\hline
\end{tabular}

2에 나타내었다. 대상 선박의 위치유지 시스템을 위해 DPS뿐만 아니라 미드쉽과 선수 사이의 인터널 터렛 계류 시스템이 적용 되어 있지만 본 연구에서는 DPS의 성능 평가가 목적이므로 계 류 시스템은 시뮬레이션에 고려하지 않았다.

\section{2 환경 하중}

\subsection{1 빙 하중}

빙 하중을 계산하기 위한 시뮬레이션은 러시아 선급 RMRS (Russia Maritime Register of Shipping)의 극지용 선박을 대상으로 한 빙 등급인 ARC7 조건을 기반으로 수행되었다(RMRS, 2016). 구체적으로, $\mathrm{ARC}$ 에서도 연중 운영이 가능하며 쇄빙선이 없는 독자적인 운용환경을 대상으로 한 빙 등급 조건을 적용하였다. 대상 해역은 빙 등급의 조건과 대상 선박의 특징을 고려하여 $\mathrm{ARC7}$ 해역 중 하나인 척치해(Chukchi Sea)로 선정되었다.

\subsubsection{GEM(GPU-Event-Mechanics) 시뮬레이터}

$\mathrm{DP}$ 성능 분석에 적용된 빙하중은 GPU-event-mechanics(GEM) 기법 기반의 시뮬레이터를 이용하여 계산되었다. GEM은 미국 선급인 $\mathrm{ABS}$ 와 캐나다Memorial 대학교의 극지용 선박 항해 경 로 예측 프로젝트에서 개발된 소프트웨어를 기반으로 제시된 새로운 수치해석 기법이다(Daley et al., 2012). GEM은 그래픽 연산 전용의 프로세서인 GPU 하드웨어를 계산에 이용해서 빠 른 계산 속도와 수많은 유빙의 동시 해석을 가능하게 한다. 시 률레이터 내에는 Fig. $4(\mathrm{a})$ 와 같이 다각형의 빙 조각들을 $2 \mathrm{D}$ 로 모델링 가능하다. 또한 유빙 크기, 밀집도 등을 무작위로 설정 하여 분포시키거나 그리드(Grid) 라인에 따라 분포시켜 Fig. 4(b) 와 같이 빙 집중도를 변경시키며 조건을 설정 가능하다. 유빙과 구조물의 충돌을 묘사하기 위해서는 다양한 입력 정보를 고려 하는 일련의 방정식들이 필요하다. 다수의 수학적 방정식들을 이용하여 유빙과 구조물의 충돌 및 유빙 간의 충돌이 묘사되며, 빙 두께, 강도, 밀도 등의 유빙의 파라미터들뿐만 아니라 선박 의 형상과 같은 데이터들을 입력하면 일련의 방정식들이 일정 한 시간 간격에 따라 계산된다. 유빙의 움직임, 파단, 유빙간의 충돌 및 선박과 유빙의 충돌 등 모든 변화는 이벤트로 간주되 며 결론적으로, 구조물과 유빙의 충돌 이벤트가 발생했을 때, 구조물이 받는 하중을 계산할 수 있다. 이러한 $\mathrm{GEM}$ 은 복잡하 고 긴 계산시간이 발생하는 조건들을 실시간보다 빠르게 계산 할 수 있어 하이퍼-실시간 계산법(Hyper-real-time method)이라고 불린다. 


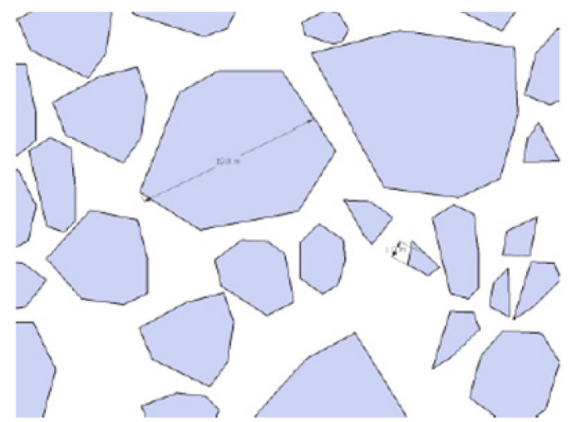

(a)

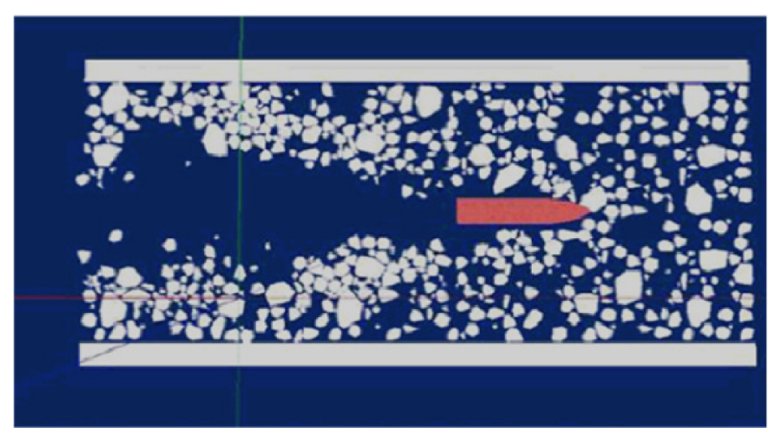

(b)

Fig. 4 2D Geometry of ice floe in GEM simulator (Daley et al., 2014)

\subsubsection{2 빙 파라미터 선정}

빙하중 산출을 위해 다양한 빙 파라미터들을 고려하였다. ITTC(International Towing Tank Conference)의 가이드라인은 빙 조건의 선박 모델 테스트에서 고려해야 할 빙 파라미터들의 목 록과 우선순위를 소개하고 있다(ITTC, 1999). 빙 조건에서의 DPS 시뮬레이터와 관련된 연구인 DYPIC 프로젝트(Jenssen et al., 2012)는 유빙 조건에서의 예인 실험에 적용되는 주요 빙 파 라미터들에 대해 언급하였다. 일반적으로 모델 테스트와 시뮬 레이션에 적용되는 주요 빙 파라미터는 빙 밀집도, 사이즈, 두 께, 밀도, 분포도, 표류속도, 표류 각도 등이다. 파라미터의 우선 순위는 모델 테스트 및 시뮬레이션 환경, 대상 모델의 목적에 따라서 달라질 수 있다. 본 연구에서 선정된 주요 빙 파라미터 는 빙 밀집도, 두께, 밀도, 표류속도, 파쇄 강도이다. 파쇄 강도 는 ITTC의 가이드라인에 명시되어 있지 않지만 DP선박의 유빙선박 충돌 시뮬레이션에 고려되는 주요 인자 중 하나이기 때문 에 본 논문의 빙 파라미터로 선정하였다(Nguyen et al., 2009).

시뮬레이션에 적용된 빙 파라미터들의 조건은 대상 해역 및 통상적인 유빙의 데이터를 기반으로 Table 3 과 같이 선정되었 다. ARC7의 1 년빙 두께는 여름과 가을은 평균 $1.7 \mathrm{~m}$, 봄과 겨울 에 평균 $1.4 \mathrm{~m}$ 이다(RMRS, 2016). 해당 범위를 포함하여 빙 두께 조건은 $1.0 \mathrm{~m}, 1.5 \mathrm{~m}, 2.0 \mathrm{~m}$ 로 선정하였다. 빙 표류속도는 척치해 의 조류속도와 관련지어 케이스를 선정하였다. 척치해의 10,000 년 주기의 조류는 약 $0.3 \sim 0.9 \mathrm{~m} / \mathrm{s}$ 이다(Jung et al., 2017). 빙 표류 속도는 조류속도와 동일한 속도로 가정하였다(Jenssen et al., 2012). 빙 파쇄 강도와 밀도의 경우 해역과 계절에 따라 상당한 변동이 존재하기 때문에, 전 세계 해역의 일반적인 유빙의 데이 터를 이용하여 선정하였다. 빙 파쇄 강도는 $1.8,2.0,2.2 \mathrm{MPa}$ 로 선정하였으며, 빙 밀도는 해수의 밀도인 $1025 \mathrm{~kg} / \mathrm{m}^{3}$ 를 초과하지 않으며 얼음의 밀도인 $920 \mathrm{~kg} / \mathrm{m}^{3}$ 를 고려하여 적절하게 분배하였 다. 선정된 빙 밀도 조건은 $850 \mathrm{~kg} / \mathrm{m}^{3}, 900 \mathrm{~kg} / \mathrm{m}^{3}, 950 \mathrm{~kg} / \mathrm{m}^{3}$ 이다.

Table 3 Principal ice parameters for simulation

\begin{tabular}{cc}
\hline \hline Ice parameter & Value \\
\hline Ice concentration $[\%]$ & 80 (Fixed) \\
Ice thickness $[\mathrm{m}]$ & $1.0,1.5,2.0$ \\
Ice drift speed $[\mathrm{m} / \mathrm{s}]$ & $0.5,0.8,0.9,1.0$ \\
Ice crushing strength $[\mathrm{MPa}]$ & $1.8,2.0,2.2$ \\
Ice density $\left[\mathrm{kg} / \mathrm{m}^{3}\right]$ & $850,900,950$ \\
\hline
\end{tabular}

빙하중은 GEM 시뮬레이터를 이용하여 산출된 Surge, Sway, Yaw 3자유도의 평균 하중 값을 사용하였다.

\subsubsection{GEM을 이용한 빙하중 산출 시뮬레이션}

$\mathrm{DP}$ 성능 분석에 필요한 빙 하중은 유빙(Pack ice) 조건의 선 박 시률레이션으로부터 산출된다. 유빙의 크기는 최소 $10 \mathrm{~m}$, 최 대 $50 \mathrm{~m}$ 내에서 무작위로 생성되도록 설정하였으며, 유빙의 모 양은 4각형에서 7각형 사이의 다각형이 무작위로 분포되도록 설정하였다. 시뮬레이션 시, 유빙 구역이 모델링된 환경에서 선 박에 대한 상대적인 빙 표류각을 구현하기 위해 선박의 Yaw각 도를 변경하며 Fig. 5와 같이 시률레이션 하였다. Yaw 각도가 변경된 선박은 유빙 구역으로 표류하며 이때의 빙하중은 시간 에 따라 기록되어 Fig. 6과 같은 시계열 형태로 산출된다(Han et al., 2017). 본 연구에 사용된 최종 빙하중 값은 산출된 시계열의 통계적인 후처리를 거친 평균 빙하중값이 사용되었다. 빙하중 은 대상 선박과 유빙이 접촉한 후 지속해서 상승한다. 유빙 구 역이 대상 선박에 의해 완전히 영향을 받게 되면 빙하중은 급

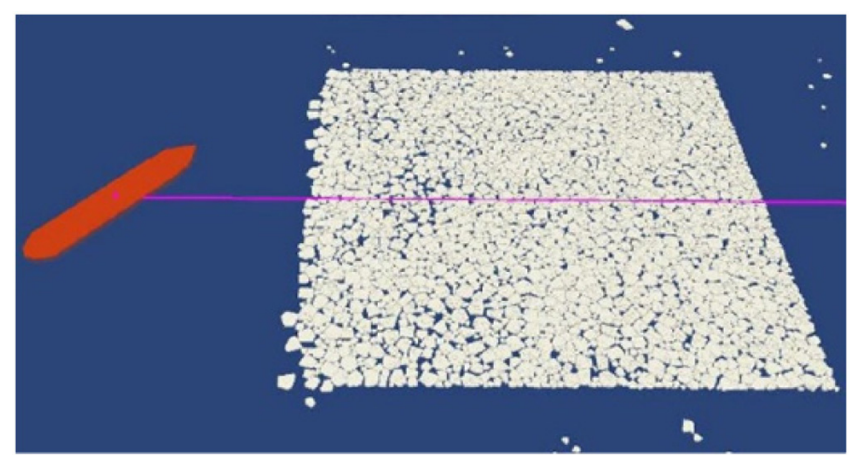

Fig. 5 Sample of GEM simulation

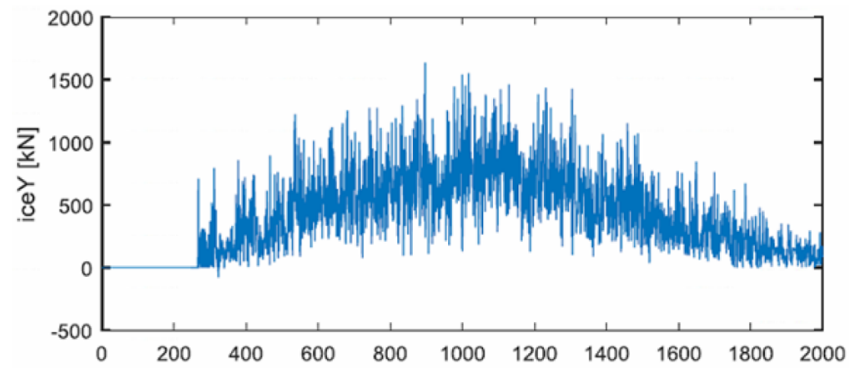

Fig. 6 GEM output example of ice load in seconds (Han et al., 2017) 
격한 변동성을 보이며 일정한 평균값을 가진다. 대상 선박이 유 빙 구역을 벗어나기 시작하면 빙하중은 다시 감소하는 경향을 보인다. 따라서, 빙하중의 시계열에서 하중의 상승과 하강 구간 을 제외하고 일정한 값 이내에서 변동하는 정상상태 구간을 선 정하여 최종적으로 평균 빙하중을 산출하였다.

\subsection{2 기타 환경 하중}

풍력은 대상 선박의 실험 및 시뮬레이션 결과로부터 구해진 Surge, Sway, Yaw 3자유도의 풍력 계수와 대상 선박의 수면 위 길이 방향, 폭 방향 투영면적으로부터 계산할 수 있다. 본 연구 에서, 풍력 계수는 대상 선박의 CFD 결과로부터 계산된 값을 이용하였고 10 도 간격으로 360 도를 고려한 총 36 개의 풍력 계 수가 사용되었다. 고려된 최대 풍속은 $50 \mathrm{~m} / \mathrm{s}$ 이며 정상풍(Steady wind) 조건이 적용되었다.

일반적으로 DPS는 고주파수대의 외력에 대한 보상을 고려하지 않는다. 따라서, 고주파수 대역인 1차 파랑 강제력은 고려되지 않 기 때문에 2 차 파랑강제력의 평균 표류력이 DP 성능 도표 산출을 위한 시뮬레이션에 사용된다. IMCA에 따르면, 파도의 조건은 Table 4에 명시되어 있는 북해를 대상으로 한 풍속과의 관계에 의 해 결정된다. 우선 풍속 조건이 결정되면 풍속-파도 관계에 따라 해당 파도의 데이터를 이용해 특정 스펙트럼을 생성시킬 수 있다. 생성된 파 스펙트럼과 평균 표류력의 전달함수를 이용해 DP 성능 분석을 위한 파력이 계산된다. 본 연구에는 JONSWAP(Joint North Sea wave project) 스펙트럼을 적용한 파력이 계산되었다.

Table 4 Wind-wave relation in IMCA

\begin{tabular}{cccc}
\hline \hline Sig. Wave height & Crossing period & Peak period & Mean wind speed \\
$H_{s}[\mathrm{~m}]$ & $T_{z}[\mathrm{~s}]$ & $T_{p}[\mathrm{~s}]$ & $V_{w}[\mathrm{~m} / \mathrm{s}]$ \\
\hline 0 & 0 & 0 & 0 \\
1.28 & 4.14 & 5.3 & 2.5 \\
1.78 & 4.89 & 6.26 & 5 \\
2.44 & 5.72 & 7.32 & 7.5 \\
3.21 & 6.57 & 8.41 & 10 \\
4.09 & 7.41 & 9.49 & 12.5 \\
5.07 & 8.25 & 10.56 & 15 \\
6.12 & 9.07 & 11.61 & 17.5 \\
7.26 & 9.87 & 12.64 & 20 \\
8.47 & 10.67 & 13.65 & 22.5 \\
9.75 & 11.44 & 14.65 & 25 \\
11.09 & 12.21 & 15.62 & 27.5 \\
12.5 & 12.96 & 16.58 & 30 \\
13.97 & 13.7 & 17.53 & 32.5 \\
15.49 & 14.42 & 18.46 & 35 \\
\hline
\end{tabular}

\section{4. 시뮬레이션 과정}

\section{1 시뮬레이션 적용 대상 빙조건}

시뮬레이션을 통해 여러 가지 조건에서 Thrust envelope와 Wind envelope를 작성하여 DP 성능에 영향을 미치는 빙 파라미
터들에 대한 분석을 수행하였다. 빙 조건에서의 DP 성능 도표 는 IMCA에 따른 기존의 분석법인 Fig. 1, Fig. 2와 같은 방식으 로 작성되지만, 전체 환경 외력 산정 과정에서 식 (2)에 따라 $\vec{F}$ ice로 명시된 빙하중을 추가하였다.

$$
0=\vec{F}_{t h}+\vec{F}_{w i}+\vec{F}_{w a}+\vec{F}_{c u}+\vec{F}_{i c e}
$$

빙하중은 빙 파라미터의 변화에 따른 GEM 시뮬레이션 결과 값을 사용하였다. 빙 하중을 산출하기 위한 빙 조건은 Table 5 와 같다. Case 3 번을 기준 데이터로 하여 각 파라미터를 변경하 면서 총 10 가지 조건의 빙 하중을 산출하였다. 유빙의 표류 각 도를 묘사하기 위해 설정하였던 선박의 각도를 0 50까지 10 도 간격으로 총 6 개의 각도에 대해 변경하며 시뮬레이션하였다. 결 과분석은 Table 6 의 결과 비교 시나리오에 따라서 진행되었다.

Table 5 Ice load cases for simulation

\begin{tabular}{cccccc}
\hline \hline $\begin{array}{c}\text { Case } \\
\text { No. }\end{array}$ & $\begin{array}{c}\text { Ice } \\
\text { thickness }\end{array}$ & Density & Drift speed & $\begin{array}{c}\text { Crushing } \\
\text { strength }\end{array}$ & Heading \\
\hline $\mathrm{m}]$ & {$\left[\mathrm{kg} / \mathrm{m}^{3}\right]$} & {$[\mathrm{m} / \mathrm{s}]$} & 0.5 & 2.0 & $0 \sim 50$ \\
{$[\mathrm{deg}]$}
\end{tabular}

Table 6 Result comparison scenario

\begin{tabular}{llccc}
\hline Ice thickness & Density & Drift speed & $\begin{array}{c}\text { Crushing } \\
\text { strength }\end{array}$ \\
\hline Case no. & $3,9,10$ & $3,5,6,7$ & $2,3,4$ & $1,3,8$ \\
\hline
\end{tabular}

\section{2 시뮬레이션 결과 분석}

본 논문은 유빙 조건이라는 특수한 환경 조건에서의 $\mathrm{DP}$ 성능 평가가 목적이다. 따라서, 선수의 유지 가능 영역에 대한 판별이 우선순위이므로 Thrust envelope을 이용한 평가를 수행하였다. 극좌표계에서 결과는 선박의 각도(Heading)에 따라 유효한 값인 50 도까지만 도표에 점선으로 경계선을 설정하여 나타내었다. 이 는 해당 선박의 경우 빙하중이 없는 조건에서도 \pm 50 도 이상의 각도에서 하중이 가해질 경우 분배 알고리즘에 의해 각 추진기 에 할당된 추력이 가용추력을 넘어선 상태인 추진기 포화가 발 생하기 때문이다. Thrust envelope에서는 결과값이 극 좌표계의 원점에 가까울수록 $\mathrm{DP}$ 성능이 좋음을 의미한다. $\mathrm{DP}$ 성능에 미 치는 빙 파라미터의 영향도 분석은 빙 파라미터 간의 평균 민감 도 비교를 통해 수행되었다. 민감도는 식 (3)에 따라 계산될 수 있다. 각 빙 파라미터마다 파라미터 변화량에 대한 최대추력 변 
Table 7 Simulation result

\begin{tabular}{ccccc}
\hline \hline & $\Delta P($ Variation) & $\Delta$ Thrust envelope & Sensitivity & $\begin{array}{c}\text { Mean sensitivity } \\
(\text { E(sensitivity)) }\end{array}$ \\
\hline \multirow{2}{*}{ Thickness } & $0.5(1 \rightarrow 1.5 \mathrm{~m})$ & 2.58 & 5.15 & 5.94 \\
& $0.5(1.5 \rightarrow 2.0 \mathrm{~m})$ & 3.36 & 6.72 & 0.90 \\
\multirow{2}{*}{ Drift speed } & $0.3(0.5 \rightarrow 0.8 \mathrm{~m} / \mathrm{s})$ & 0.27 & 62.9 & 40.44 \\
& $0.1(0.8 \rightarrow 0.9 \mathrm{~m} / \mathrm{s})$ & 6.29 & 57.5 & 2.67 \\
\hline \multirow{2}{*}{ Crushing strength } & $0.1(0.9 \rightarrow 1.0 \mathrm{~m} / \mathrm{s})$ & 5.75 & 2.68 & 2.65 \\
\hline \multirow{2}{*}{ Ice density } & $0.2(1.8 \rightarrow 2.0 \mathrm{MPa})$ & 0.54 & 0.01 & 0.01 \\
& $0.2(2.0 \rightarrow 2.2 \mathrm{MPa})$ & 0.53 & 0.01 & \multirow{2}{*}{0.11} \\
\hline
\end{tabular}

화량 비를 의미하며 최종적으로 민감도의 평균값을 계산하여 Table 7에 나타내었다. AThrust envelope은 Thrust envelope의 값 의 변화량을 의미하며 최대 추력 변화량이라 칭한다. 민감도가 낮을수록 파라미터의 변화량에 따른 최대추력의 변화가 크지 않 으므로 해당 파라미터가 추력에 미치는 영향이 적다는 것을 의 미한다.

$$
\text { Mean Sensitivity }=E\left(\frac{\Delta \text { Thrust envelops }}{\Delta P}\right)
$$

$\Delta$ Thrust $=$ Variation of thrust envelope value $\Delta P=$ Variation of parameter value

Fig. 7-10은 각 빙 파라미터들의 변화에 따른 Thrust envelope 을 나타낸다. 각 결과 그래프의 아래에는 환경조건을 정의하였 으며, $V_{c}$ 는 조류의 속도, $V_{w}$ 는 풍속, $H_{s}$ 는 유의파고, $T_{z}$ 는 영점상 교차주기를 말한다. Table 7의 최대 추력 변화량과 결과 그래프 들로부터, 모든 빙 파라미터들의 파라미터 변화량 $(\Delta P)$ 이 발생 할수록 최대 추력변화량( $\Delta$ Thrust envelope)이 모두 양의 값을 가지므로 DP 성능이 감소하는 것을 알 수 있다. 하지만, 파라미 터들에 따라 그 민감도의 차이가 존재하며, 민감도 분석 결과로 부터 특히 Fig. 9-10의 파쇄 강도, 밀도의 경우 표류속도보다 민 감도가 미소한 값을 가지는 것을 알 수 있다. 따라서, 해당 파라 미터들의 변화로 인한 DP 성능의 변화는 둔감한 경향을 보이며 $\mathrm{DP}$ 성능에 미치는 영향이 작은 것으로 판단된다. 특히, 밀도의 경우 민감도의 값이 매우 미소하므로 빙조건이 추가된 DP 시뮬 레이션 시 통상적으로 사용되는 얼음 밀도인 $920 \mathrm{~kg} / \mathrm{m}^{3}$ 로 고정 하여 시뮬레이션하여도 DP 성능에는 큰 영향을 미치지 않을 것 으로 판단된다.

Table 7의 민감도 수치에 따르면 빙 두께의 경우 표류속도에 비해 8 배 작은 값을 가지며 파라미터 변화량에 따른 추진기 포 화(Saturation) 각도의 변동이 없어 DP 성능이 민감하게 반응하 지는 않지만 Fig. 7에 나타난 두께 변화에 의한 Thrust envelope 의 뚜렷한 변화가 관찰된다. 따라서, 빙 두께는 시뮬레이션의 중요한 파라미터 중 하나가 될 수 있으며 적용된 대상 해역의 유빙 두께 데이터를 기반으로 하여 시뮬레이션 해야 한다.

Table 7에 의하면 빙 표류 속도의 결과에서, 표류 속도의 파 라미터 변화량이 0.3 일 때, 민감도는 0.90 이며 파라미터 변화량

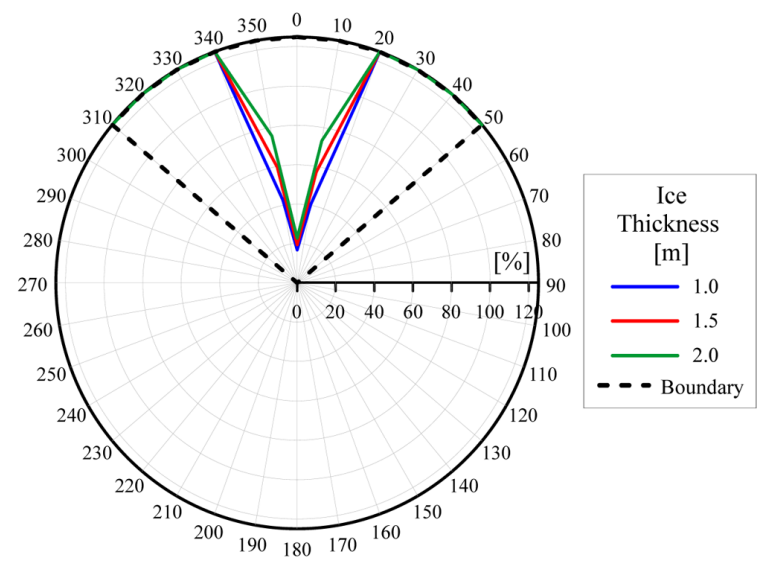

$\mathrm{V}_{\mathrm{c}}: 1 \mathrm{~m} / \mathrm{s}, \mathrm{V}_{\mathrm{w}}: 10 \mathrm{~m} / \mathrm{s}, \mathrm{H}_{\mathrm{s}}: 3.21 \mathrm{~m}, \mathrm{~T}_{\mathrm{z}}: 6.57 \mathrm{~s}$

Fig. 7 Thrust envelope with respect to ice thickness

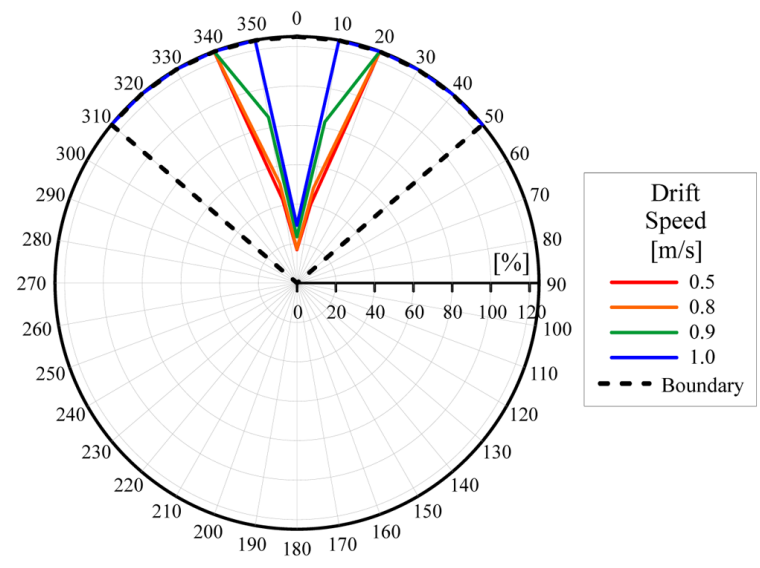

$\mathrm{V}_{\mathrm{c}}: 1 \mathrm{~m} / \mathrm{s}, \mathrm{V}_{\mathrm{w}}: 10 \mathrm{~m} / \mathrm{s}, \mathrm{H}_{\mathrm{s}}: 3.21 \mathrm{~m}, \mathrm{~T}_{\mathrm{z}}: 6.57 \mathrm{~s}$

Fig. 8 Thrust envelope with respect to ice drift speed

이 0.1 일 때, 민감도는 각 $62.9,57.5$ 로 변화량 차이에 따른 민감도 차이가 상당히 크게 나타나고 있음을 알 수 있다. 이로부터, 결과 값 산출에 사용한 통계적 처리의 합리성을 평가할 필요가 있다. 빙하중은 시간에 따른 변동성이 극심한 환경 조건 중 하나이기 때문에, 조건에 따라 임펄스 반응을 할 수도 있으며, 비연속적인 형태를 띠기도 한다. 따라서, 평균값을 취하는 과정에서 비합리 적인 값이 산출될 수 있기 때문에, 본 연구의 결과 분석에 사용 


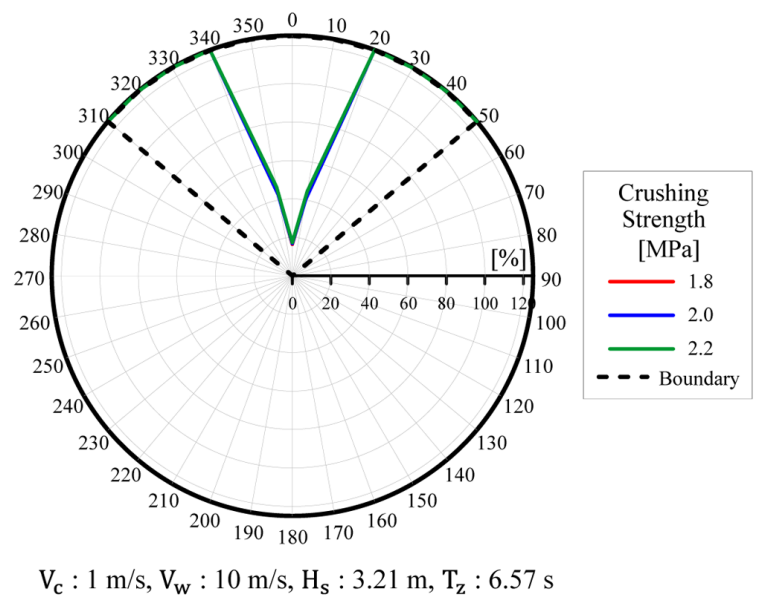

Fig. 9 Thrust envelope with respect to crushing strength

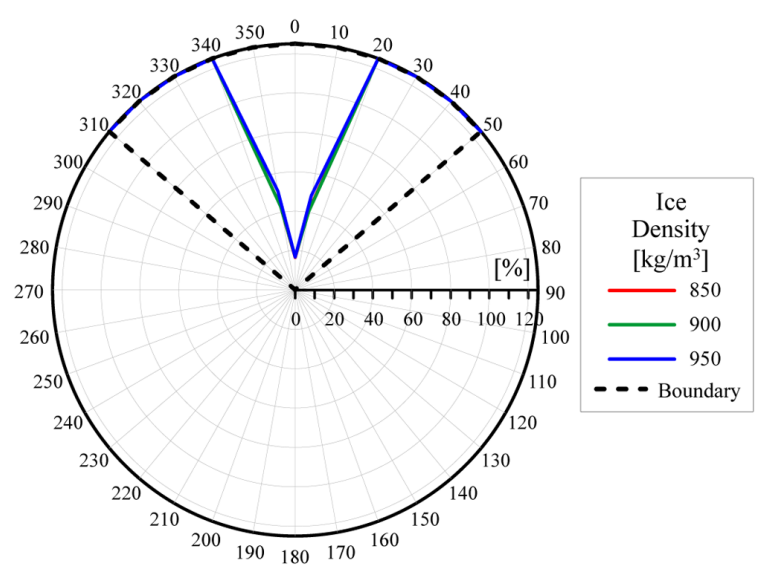

$\mathrm{V}_{\mathrm{c}}: 1 \mathrm{~m} / \mathrm{s}, \mathrm{V}_{\mathrm{w}}: 10 \mathrm{~m} / \mathrm{s}, \mathrm{H}_{\mathrm{s}}: 3.21 \mathrm{~m}, \mathrm{~T}_{\mathrm{z}}: 6.57 \mathrm{~s}$

Fig. 10 Thrust envelope with respect to ice density

된 표류 속도는 비선형성을 띠는 구간을 제외한 $0.8 \mathrm{~m} / \mathrm{s}, 0.9 \mathrm{~m} / \mathrm{s}$, $1.0 \mathrm{~m} / \mathrm{s}$ 의 값을 사용하였다.

선정된 표류 속도를 적용한 분석 결과로부터, 빙 표류속도는 시뮬레이션에 사용된 빙 파라미터 중 가장 높은 민감도를 나타 낸다. 또한, Fig. 8으로부터 추진기 포화 각도의 변동도 나타난 다. 이는 표류 속도에 대한 추력의 변화가 굉장히 민감하며 표 류속도가 DP 성능 감소에 가장 큰 영향을 미치는 파라미터임을 의미한다. 이는 빙 표류속도가 조류 속도와 일치하는 것으로 가 정한 것과 상관이 있으며, 대상 해역의 조류 속도에 대한 분석 이 상세히 이루어져야 함을 의미한다. 따라서, 표류속도를 고려 한 시뮬레이션 시, 본 시뮬레이션에서 사용된 파라미터 변화량 보다 더 미세한 변화량을 설정하여 다양한 표류속도를 고려해 야 한다.

분석 결과로부터 유빙 조건이 추가된 DP 시률레이션 시에는 빙 두께, 표류속도를 중점적으로 고려해야 하며 특히 표류속도는 더욱 미세한 파라미터 변화량을 설정하여 시뮬레이션할 필요가 있다. 파쇄 강도, 밀도는 큰 영향을 미치지 않으며, 특히 밀도는 $\mathrm{DP}$ 성능 변화에 매우 둔감한 경향을 보이므로 시뮬레이션 시 고 려 대상에서 제외하거나 고정된 한 값을 적용한다면 고려해야 하 는 유빙의 조건들이 간소화될 수 있을 것으로 판단된다.
하지만, 본 시뮬레이션은 앞서 언급한 통계적 처리의 한계점 을 동반하고 있다. 표류 속도뿐만 아니라 대부분의 빙 파라미터 에서 파라미터 변화량에 따른 추력의 변화량이 비선형성을 띠 고 있다. 이를 최소화하기 위해서 산출되는 빙하중의 평균 하중 값이 아닌 유의 빙하중값 혹은 제곱평균제곱근(RMS)와 같은 다 른 통계적인 처리를 하거나, 비선형성과 동적인 요소가 포함된 시계열 데이터를 이용한 DP 성능 분석법이 요구된다.

\section{5. 결 론}

본 연구에서는 다양한 빙 파라미터들의 변동에 따른 DP 성능 의 분석을 위한 시뮬레이션을 수행하였다. 통상적인 DP 성능 도표를 그리기 위한 절차인 IMCA의 규정서 및 성능 도표의 종 류를 소개하였으며 기존의 방법에 유빙 조건이 추가된 성능 도 표를 그리기 위한 과정에 관해 설명하였다. 빙 하중은 전문 빙 하중 추정 소프트웨어인 $\mathrm{GEM}$ 을 이용해 계산되었다. 빙 조건에 따라 설정된 파라미터들을 변경하며 산출된 시계열 데이터를 통계적인 후처리로 가공하여 얻은 평균 하중을 사용하였다. 산 출된 평균 하중이 적용된 환경 조건으로부터 Wind envelope과 Thrust envelope을 작성하였으며 이를 기반으로 빙 파라미터들 의 변화에 대한 DP 성능의 변화를 분석하였다.

시뮬레이션 결과 분석으로부터 아래의 5 가지 결론을 도출하 였다.

(1) 모든 빙 파라미터들의 값이 증가하였을 때, DP 성능은 감 소하였다.

(2) 빙 표류속도는 DP 성능에 매우 민감하며 가장 큰 영향을 끼친다.

(3) 빙 두께는 시뮬레이션 시 반드시 고려해야할 파라미터 중 하나이다.

(4) 빙 파쇄 강도와 밀도는 DP 성능에 큰 영향을 미치지 않는다.

(5) 빙하중 시계열로부터 빙하중 계산 시, 변동성(Variation)을 고려할 수 있는 통계적 특성치가 필요하다.

5 가지의 결과를 수립하였다. 결과로부터, 유빙 조건이 고려된 $\mathrm{DP}$ 시률레이션에는 빙 두께, 표류속도를 우선순위로 고려해야 하며 빙 파쇄 강도, 밀도는 DP 시뮬레이션 시 고정값을 사용하 거나 DP 성능 분석을 위한 주요 파라미터에서 제외할 수 있을 것으로 판단된다.

시뮬레이션 과정에서 빙하중은 시계열의 평균치를 사용하여 산출되었다. 이로 인해 평균값의 변동성이 발생할 수 있기 때문 에, 추후, 유의 빙하중, 제곱평균제곱근과 같은 다른 통계적 기 법을 이용하여 계산된 빙하중을 기반으로 빙 파라미터의 변화 에 대한 $\mathrm{DP}$ 성능 분석을 수행하여 기존의 방법과 비교할 계획 이다.

\section{후기}

본 연구는 산업통상자원부 산업기술혁신사업(과제번호: 10063 405) '위치유지와 계류 시스템을 적용하여 $\mathrm{ARC7}$ 조건에서 연중 운용이 가능한 북극해 기반 부유식 해양구조물 형상 개발' 과제 의 지원으로 수행되었음을 밝힙니다. 


\section{References}

Daley, C., Alawneh, S., Peters, D., Quinton, B., Colbourne, B., 2012. GPU Modeling of Ship Operations in Pack Ice. International Conference and Exhibition on Performance of Ships and Structures in Ice, Banff Alberta Canada, 20-23.

Daley, C., Alawneh, S., Peters, D., Colbourne, B., 2014. GPUEvent-Mechanics Evaluation of Ice Impact Load Statistics. OTC Arctic Technology Conference, Offshore Technology Conference.

Han, S.L., Kim, H.J., Lee, D.Y., Kim, B.K., 2017. Capability Analysis of Dynamic Positioning for the Arctic FPSO in ICE. Proceeding of the 24th International Conference on Port and Ocean Engineering under Arctic Conditions, Busan Korea. International Marine Contractors Association(IMCA)., 2000. Specification for DP Capability Plots. IMCA M 140.

International Towing Tank Conference(ITTC)., 1999. Testing and Extrapolation Methods Ice Testing General Guidelines. ITTC Recommended Procedures and Guidelines, 7.5-02-04-01.

Jenssen, N.A., Hals, T., Jochmann, P., Haase, A., Dal Santo, X., Kerkeni, S., Doucy,O., Gürtner, A., Hetschel, S.S., Moslet,
P.O., Metrikin, I., Løset, S., 2012. DYPIC-A Multi-National R\&D Project on DP Technology in Ice. Dynamic Positioning Conference, Marine Technology Society, Houston Texas.

Jung, K.H., Lee, M.K., Shin, S.Y., 2017. Design Considerations and Analysis of Arctic FPSO's Turret Moorisng System. The Autumn Conference of The Korea Society of Ocean Engineers, Geoje Korea.

Kerkeni, S., Metrikin, I., Jochmann, P., 2013. Capability Plots of Dynamic Positioning in Ice. ASME Paper, OMAE2013-10912.

Nguyen, D.T., Sørbø, A.H., Sørensen, A.J., 2009. Modelling and Control for Dynamic Positioned Vessels in Level Ice. IFAC Proceedings, 42(18), 229-236.

RMRS., 2016, Rules for the Classification and Construction of Sea-Going Ships, Part I - Cassification. Russia Maritime Register of Shipping, Russia.

Su, B., Kjerstad, Ø.K., Skjetne, R., Berg, T.E., 2013. Ice-going Capability Assessment and DP-Ice Capability Plot for a Double Acting Intervention Vessel in Level Ice. Proceedings of the International Conference on Port and Ocean Engineering Under Arctic Conditions. 